\title{
Protocol
}

\section{Effect of Ankle Plantar Flexor Spasticity Level on Balance in Patients With Stroke: Protocol for a Cross-Sectional Study}

Ashraf Mahmoudzadeh ${ }^{1}, \mathrm{PhD}$; Noureddin Nakhostin Ansari ${ }^{1,2}, \mathrm{PhD}$; Soofia Naghdi ${ }^{1,2}, \mathrm{PhD}$; Ebrahim Sadeghi-Demneh ${ }^{3}$, $\mathrm{PhD}$; Omid Motamedzadeh ${ }^{1}, \mathrm{PhD}$; Brandon S Shaw ${ }^{4}, \mathrm{PhD}$; Ardalan Shariat ${ }^{2}, \mathrm{PhD}$; Ina Shaw ${ }^{4}, \mathrm{PhD}$

\footnotetext{
${ }^{1}$ Department of Physiotherapy, School of Rehabilitation, Tehran University of Medical Sciences, Tehran, Iran

${ }^{2}$ Neuroscience Institute, Sports Medicine Research Center, Tehran University of Medical Sciences, Tehran, Iran

${ }^{3}$ Prosthetics and Orthotics Department, Musculoskeletal Research Center, Isfahan University of Medical Sciences, Isfahan, Iran

${ }^{4}$ Department of Human Movement Science, University of Zululand, Kwazulu-Natal, South Africa
}

\section{Corresponding Author:}

Noureddin Nakhostin Ansari, PhD

Department of Physiotherapy

School of Rehabilitation

Tehran University of Medical Sciences

Enghelab Ave, Pich-e-shemiran

Tehran, 11489

Iran

Phone: 982177533939

Fax: 982177727009

Email: nakhostin@sina.tums.ac.ir

\section{Abstract}

Background: The lower limb spasticity after stroke can affect the balance and gait of patients with stroke.

Objective: The aim of this study is to assess the effects of ankle plantar flexor spasticity level on balance in patients with stroke. Methods: Patients with stroke were recruited from neurology and physiotherapy clinics in Tehran, Iran. Based on the level of ankle plantar flexor spasticity according to the Modified Modified Ashworth Scale (MMAS), the eligible patients with stroke were divided into 2 groups: high spasticity (MMAS score $\geq 2$ ) and low spasticity (MMAS score<2). The primary outcome measures were the MMAS scores, Activities-Specific Balance Confidence questionnaire scores, eyes-open and eyes-closed posturography measures, and Timed Up and Go test results. The secondary outcome measures were the ankle passive range of motion and ankle joint proprioception. The $t$ test, mixed model univariate analysis of variance, and Spearman rank correlation were used for statistical analysis.

Results: Data collection and statistical analysis are complete. The interpretation of results is underway. We expect the results to be published in winter 2020.

Conclusions: We believe that patients with high ankle plantar flexor spasticity after stroke will demonstrate greater balance dysfunction, which will worsen with impaired proprioception, passive range of motion, and eyes closed.

International Registered Report Identifier (IRRID): RR1-10.2196/16045

(JMIR Res Protoc 2020;9(8):e16045) doi: 10.2196/16045

\section{KEYWORDS}

stroke; muscle spasticity; balance; rehabilitation; lower extremity; posturography

\section{Introduction}

Stroke is the most common cause of disability in adults worldwide. Spasticity is one of the most important motor complications after stroke and negatively affects patients' quality of life $[1,2]$. Spasticity is a velocity-dependent increase in muscle tone, resulting from hyperexcitability of the stretch reflex [3]. The lower limb spasticity has a critical role in balance and gait dysfunction of patients after stroke [4]. It decreases the joint range of motion (ROM) and increases the stiffness of the muscles and tissues around the joints. The impairment in balance and postural control is an important symptom in patients after 
stroke, because it can delay the recovery process in performing daily activities and increases the risk of falling [5]. A reduced balance control is associated with greater disability [6].

The somatosensory system, especially proprioception, is impaired in patients with stroke [7]. This impairment affects the motor function of the patients and prolongs their rehabilitation period. Consequently, the balance control is difficult for the patients with stroke due to impaired proprioception and inappropriate ankle strategies [8].

The evaluation of balance and of the factors contributing to the balance disorders, such as balance nonconfidence, in patients after stroke is necessary. The balance confidence indicates the patients' confidence to maintain their balance and stability. Balance nonconfidence can affect both static as well as dynamic balance and subsequently increases the chance of falling and disability. Decrease of static and dynamic balance is a significant risk factor of falling and a functional limitation of daily activity $[9,10]$. Balance has a direct relationship with functions such as walking and climbing the stairs [11]. Balance in patients with stroke is the key factor in the prediction of rehabilitation period and functional outcomes [12].

The lower limb spasticity can affect the gait quality and balance of patients after stroke [13]. The role of spasticity in falling and the direct relationship between the severity of spasticity and the history of falling have been demonstrated [14,15]. Rahimzadeh Khiabani et al [16] evaluated the relationship between spasticity severity and balance in patients with stroke. However, this study had several drawbacks. The severity of spasticity was measured based on the Modified Ashworth Scale (MAS), despite the debate on the scale's reliability and validity [17] and the caution against its use for assessing spasticity [18]. Furthermore, only static balance, not proprioception and ankle ROM, was evaluated. Therefore, the main objective of this study protocol is to investigate the effects of ankle plantar flexor spasticity level on the balance of patients with stroke. We hypothesized that the patients with high level of ankle plantar flexor spasticity have greater balance dysfunctions, especially in the eyes-closed condition, and that their balance confidence is lower than that of the patients with a low level of spasticity in the eyes-open condition.

There are no optimal tools for assessing balance in patients with stroke. This study assessed the balance using valid clinical tools and instrumented posturography, as the objective measurement of balance is important to detect dysfunctions. Instrumented posturography that uses a force plate is inexpensive and easily available. Therefore, it was used to quantify postural sways through the measurement of center-of-pressure displacements during quiet standing. Balance dysfunctions in the patients with stroke are frequently characterized by deviations and instability of the center of pressure. Therefore, using the instrumented posturography for assessing the static balance is relevant.

\section{Methods}

\section{Study Design}

A cross-sectional study was designed to compare the static as well as dynamic balance, balance confidence, ankle proprioception, and passive ROM between 2 groups of patients with the high and low levels of ankle plantar flexor spasticity after stroke.

\section{Setting}

The measurements were be taken at the Biomechanics and Analysis of Human Motion Laboratory, School of Rehabilitation, Tehran University of Medical Sciences in Iran.

\section{Approval of Study Protocol}

The study protocol was approved by the Review Board, School of Rehabilitation, Tehran University of Medical Sciences and the Ethics Committee of Tehran University of Medical Sciences (Reference number: IR.TUMS.FNM.REC.1397.012).

\section{Informed Consent}

All eligible participants provided a written formal consent after receiving information about the research procedure. We explained the study details to participants before taking the measurements.

\section{Participants}

Participants with stroke were recruited from the neurology and physiotherapy clinics in Tehran, Iran. Participants were screened for eligibility. The patients were divided into 2 groups based on their level of ankle plantar flexor spasticity according to the Modified Modified Ashworth Scale (MMAS): high spasticity (MMAS score $\geq 2$ ) and low spasticity (MMAS score<2).

The inclusion criteria were as follows: first-ever unilateral stroke (hemorrhagic/ischemic), ankle plantar flexor spasticity $\geq 1$ based on the MMAS, walking ability, no fixed contracture in the ankle, independent standing with eyes open/closed, ability to understand and follow the commands, and no pain in the lower limbs. Participants with vision problems or depression as well as those taking antispastic medications or undergoing a rehabilitation program focused on balance and proprioception were excluded.

The physiotherapy and neurology clinics in Tehran were contacted for referring the patients with stroke who were willing to participate in the study. The principal investigator and physiotherapist responsible for assessing the patients and performing the experiments called the heads of these clinics to request cooperation and to describe the eligibility criteria. Moreover, the study aims and eligibility criteria for inclusion of patients were provided in the written form to the heads of the clinics.

\section{Sample Size}

Considering the data from the previous study [16], the sample size was estimated to be $28\left(n=14\right.$ in each group; $Z_{\alpha}=1.96$; $\alpha=.05 ; \mathrm{Z}_{\beta}=.842$; standard effect size $=1.067$ ).

\section{Procedures}

The patients were interviewed to collect demographic data, including age, gender, height, weight, time since the onset of stroke, etiology (ie, ischemic or hemorrhagic), and the affected side. Patients were assigned to one of the following groups: high spasticity (MMAS score $\geq 2$ ) and low spasticity (MMAS score $<2)$. The severity of ankle plantar flexor spasticity was 
measured after making the patients rest in bed for 5 minutes in supine position with their shoes taken off [19]. Subsequently, the Activities-Specific Balance Confidence (ABC) questionnaire [20] was administered, followed by the measurements of affected ankle proprioception, passive ROM, posturography, and Timed Up and Go (TUG) test (Figure 1). An experienced physiotherapist performed all the tests.

Figure 1. Representation of the study protocol. ABC: Activities-Specific Balance Confidence; ROM: range of motion; TUG: Timed Up and Go.

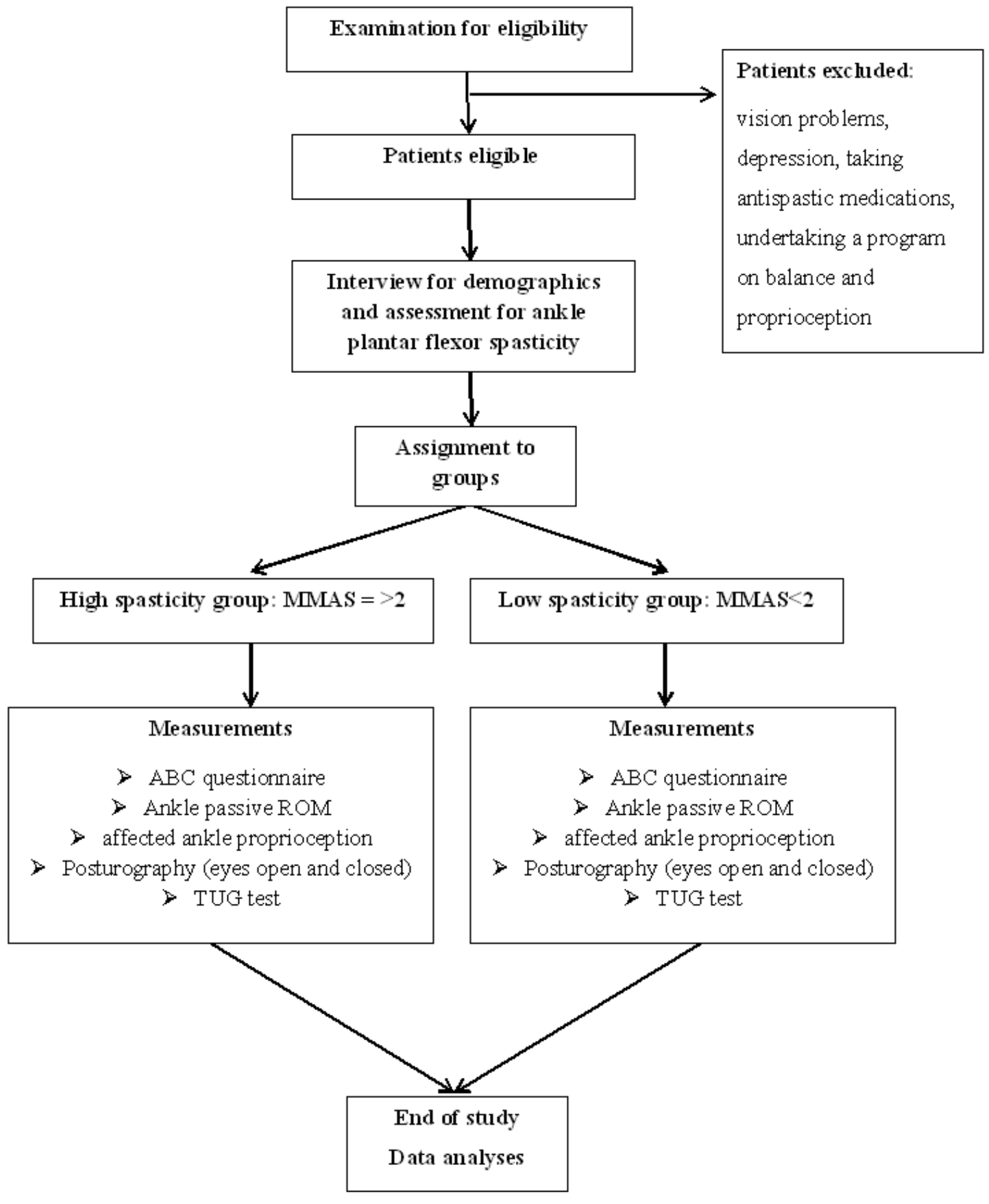

\section{Outcome Measures}

The primary outcome measures were the MMAS scores, ABC questionnaire, posturography measures in open- and closed-eyes conditions, and TUG test. The secondary outcome measures were the ankle passive ROM and ankle joint proprioception. Table 1 summarizes the outcomes and how they were measured in the study. 
Table 1. Summary of the outcome measures.

\begin{tabular}{ll}
\hline Outcomes & Scale of measurement \\
\hline Primary outcomes & MMAS $^{\mathrm{a}}$ \\
Spasticity & $\mathrm{ABC}^{\mathrm{b}}$ questionnaire \\
Balance confidence & Posturography with eyes open and closed $_{\text {Static balance }}$ \\
Dynamic balance & $\mathrm{TUG}^{\mathrm{c}}$ test \\
Secondary outcomes & \\
Passive ROM & \\
Ankle proprioception & Standard goniometer \\
\hline
\end{tabular}

${ }^{a}$ MMAS: Modified Modified Ashworth Scale.

${ }^{\mathrm{b}} \mathrm{ABC}$ : Activities-Specific Balance Confidence.

${ }^{\mathrm{c}}$ TUG: Timed Up and Go.

${ }^{\mathrm{d}} \mathrm{ROM}$ : range of motion.

\section{Spasticity}

The affected ankle plantar flexor spasticity was assessed by an experienced physiotherapist using the reliable and valid MMAS $[21,22]$. To assess the spasticity severity, the physiotherapist stood on the affected side, stabilized the affected ankle with one hand, and moved it from maximum possible plantar flexion to maximum possible dorsiflexion, counting to 1001 [23]. The definitions of spasticity grades of MMAS are presented in Table 2.

Table 2. Modified Modified Ashworth Scale (MMAS) to assess the level of spasticity [17].

\begin{tabular}{ll}
\hline Grades & Definitions \\
\hline 0 & No increase in muscle tone. \\
1 & $\begin{array}{l}\text { Slight increase in muscle tone, manifested by a catch-and-release or by minimal resistance at the end of the ROM } \\
\text { part(s) is moved in flexion or extension. }\end{array}$ \\
& $\begin{array}{l}\text { Marked increase in muscle tone, manifested by a catch in the middle range and resistance throughout the remainder of the ROM, but } \\
\text { affected part(s) is easily moved. }\end{array}$ \\
3 & Considerable increase in muscle tone; passive movement is difficult. \\
4 & Affected part(s) is rigid in flexion or extension. \\
\hline
\end{tabular}

${ }^{\mathrm{a}} \mathrm{ROM}$ : range of motion.

\section{Balance Confidence}

The ABC questionnaire, which is reliable and valid, was used to assess the balance confidence of patients with stroke in performing their daily activities $[20,24]$. The ABC questionnaire included 16 questions asking the subjects to score their confidence from $0 \%$ (no confidence) to $100 \%$ (complete confidence). To calculate the total score in percent, the following formula was used: (total score/16) $\times 100$.

\section{Posturography}

The static balance of patients was evaluated by posturography. The use of force plate in balance measurement of the patients with stroke has been demonstrated [25]. The physiotherapist asked each patient to stand on the force plate with bare feet, heels apart by $9 \mathrm{~cm}$ and at $30^{\circ}$ angle, and upper limbs comfortably along the body. The patients were asked to look at a point on the wall at a distance of $2 \mathrm{~m}$ during the test with eyes open as well as with eyes closed. Open- or closed-eyes condition was randomly applied with 2-minute rest interval between the conditions. Each condition was repeated 3 times (with a 20 -second interval), and the duration of each repetition was 20 seconds. Velocity (in centimeters per second) and the anteroposterior and mediolateral displacements (in centimeters) were recorded 3 times, and an average was calculated [25].

\section{TUG Test}

Dynamic balance of patients was measured by TUG Test, which has been proven reliable in patients with stroke [26]. The patient was asked to sit comfortably on the chair with feet resting on the floor. Then the patient was asked to get up from the chair, walk a 3-meter distance, turn around, go back to the same chair, and sit down. The time in seconds was recorded using a stopwatch from the moment the patient got up from the chair to the moment he or she sat back on the chair.

\section{Ankle ROM}

The ankle passive ROM in degree was measured in the supine position with knee extended using a standard goniometer. Axis of the goniometer was located on the lateral malleolus; the stable 
arm, along the head of the fibula; and the moving arm, along the fifth metatarsal. The physiotherapist stabilized the affected leg by one hand and moved ankle passively to maximum possible dorsiflexion by the other hand [27].

\section{Ankle Joint Proprioception}

The ankle joint proprioception was measured with the patient sitting on the edge of bed with eyes closed. The electrogoniometer was connected to the longitudinal axis of the tibia and the fifth metatarsal. The physiotherapist slowly and randomly moved the ankle to one of the following angles: $5^{\circ}$ plantar flexion, $15^{\circ}$ plantar flexion, or $15^{\circ}$ dorsiflexion angles. The examiner then held the ankle in that position for 5 seconds and asked the patient to note the ankle position. The ankle was moved passively to the starting position. The ankle was moved again to the desired position, and the patient was asked to report the position. The difference between the starting and the patient-reported position was recorded as an error value. These steps were repeated for 3 times, and the average error (in degree) over those 3 repetitions was considered as a reconstruction error of that angle [28]. The same procedure was performed for all angles with 1-minute rest interval, and the average error was recorded for each angle.

\section{Statistical Analysis}

SPSS version 22 (SPSS Inc) was used for the data analysis. The normal distribution was analyzed using the Shapiro-Wilk test. The $t$ test was used to examine the differences between 2 groups. Mixed model univariate analysis of variance (ANOVA) was used to analyze the effect of spasticity level of ankle plantar flexor muscles on the postural sway indicators in open- and closed-eyes conditions. The relationship between the severity of spasticity with the $\mathrm{ABC}$ scores, ankle proprioception, passive ROM, and TUG test were analyzed with Spearman rank correlation. The statistical significance was defined at $\alpha<.05$.

\section{Results}

Data collection and statistical analysis are complete. The interpretation of results is underway. The demographic characteristics of the participants will be calculated and provided. Descriptive results for all clinical and posturography measures will be reported and illustrated in the tables. The differences between 2 groups on the outcome measures will be analyzed and reported. The results of correlation coefficients between spasticity severity and clinical measures will be calculated and reported. We expect results to be published in winter 2020 .

\section{Discussion}

This study protocol will compare the static and dynamic balance in patients with stroke with high and low levels of plantar flexor spasticity. The results of this study would be relevant to clinicians addressing the challenges of spasticity and neurorehabilitation in patients after stroke.

There are a few studies focusing on the role of severity of spasticity on the poststroke balance dysfunction. Depression, gait asymmetry, and spasticity are 3 independent factors for predicting falls in patients with stroke [15]. Spasticity is a contributing factor to gait asymmetry [29,30]. It follows that the spasticity may be considered as one of the main predictors of falling, impairment in independent walking, and disability. Therefore, considering the role of lower limb spasticity in balance and gait dysfunctions of patients after stroke, the findings of this study will be important for both clinicians and patients to manage the plantar flexor spasticity, improve the balance, and enhance the walking ability and quality of life of the patients with stroke.

We have hypothesized that the balance dysfunction will be greater in the patients with high ankle plantar flexor spasticity than in the patients with low ankle plantar flexor spasticity. Further, the balance dysfunction will be greater with eyes closed than with eyes open. Additionally, the proprioception is reduced in the patients with stroke [31]. This impairment in proprioception is greater in the patients with higher ankle plantar flexor spasticity [32]. Consequently, we expect that the balance confidence will be lower in the group with high ankle plantar flexor spasticity. If the role of spasticity level in motor function of the patients with stroke is verified, it can help physiotherapists take necessary interventions to manage the ankle plantar flexor spasticity and improve proprioception. Such interventions can reduce the risk of falling and improve balance and mobility.

This study used a single-force platform. Thus, posturography measure was a net characteristic of both affected (paretic) and nonaffected feet. With 2 force plates ( 1 for each limb), the posturography characteristics of the affected foot and the nonaffected foot can be assessed for the 2 groups. These results can be then compared with those of neurologically healthy subjects.

The patients with high ankle plantar flexor spasticity will demonstrate greater static and dynamic balance dysfunctions than those of the patients with low spasticity, particularly, with eyes closed. The findings of this study will have implications for practice and research in the treatment of balance dysfunctions in patients with ankle plantar flexor spasticity after stroke.

\section{Acknowledgments}

We would like to thank the Research Deputy of Tehran University of Medical Sciences for supporting this study.

\section{Authors' Contributions}

NNA, SN, and AM contributed to the study conception and the design. AM drafted the manuscript. NNA read and revised the manuscript critically. All authors reviewed and commented upon the manuscript for important intellectual content and gave approval of the final manuscript for submission. 


\section{Conflicts of Interest}

None declared.

\section{References}

1. Zorowitz RD, Gillard PJ, Brainin M. Poststroke spasticity: sequelae and burden on stroke survivors and caregivers. Neurology 2013 Jan 15;80(3 Suppl 2):S45-S52. [doi: 10.1212/WNL.0b013e3182764c86] [Medline: 23319485]

2. Li S. Spasticity, Motor Recovery, and Neural Plasticity after Stroke. Front Neurol 2017;8:120 [FREE Full text] [doi: 10.3389/fneur.2017.00120] [Medline: 28421032]

3. Lance JW. The control of muscle tone, reflexes, and movement: Robert Wartenberg Lecture. Neurology 1980 Dec;30(12):1303-1313. [doi: 10.1212/wnl.30.12.1303] [Medline: $\underline{7192811]}$

4. Soyuer F, Oztürk A. The effect of spasticity, sense and walking aids in falls of people after chronic stroke. Disabil Rehabil 2007 May 15;29(9):679-687. [doi: 10.1080/09638280600925860] [Medline: 17453990 ]

5. Lamb SE, Ferrucci L, Volapto S, Fried LP, Guralnik JM, Women's HealthAging Study. Risk factors for falling in home-dwelling older women with stroke: the Women's Health and Aging Study. Stroke 2003 Feb;34(2):494-501. [Medline: 12574566]

6. Tyson SF, Hanley M, Chillala J, Selley A, Tallis RC. Balance disability after stroke. Phys Ther 2006 Jan;86(1):30-38. [doi: 10.1093/ptj/86.1.30] [Medline: 16386060]

7. Sullivan JE, Hedman LD. Sensory dysfunction following stroke: incidence, significance, examination, and intervention. Top Stroke Rehabil 2008;15(3):200-217. [doi: 10.1310/tsr1503-200] [Medline: 18647725]

8. Lee KB, Park YH, Song EK, Yoon TR, Jung KI. Static and dynamic postural balance after successful mobile-bearing total ankle arthroplasty. Arch Phys Med Rehabil 2010 Apr;91(4):519-522. [doi: 10.1016/j.apmr.2009.12.017] [Medline: 20382281]

9. Schinkel-Ivy A, Inness EL, Mansfield A. Relationships between fear of falling, balance confidence, and control of balance, gait, and reactive stepping in individuals with sub-acute stroke. Gait Posture 2016 Jan;43:154-159 [REEE Full text] [doi: 10.1016/j.gaitpost.2015.09.015] [Medline: 26482234]

10. Frändin K, Grönstedt H, Helbostad JL, Bergland A, Andresen M, Puggaard L, et al. Long-Term Effects of Individually Tailored Physical Training and Activity on Physical Function, Well-Being and Cognition in Scandinavian Nursing Home Residents: A Randomized Controlled Trial. Gerontology 2016;62(6):571-580. [doi: 10.1159/000443611] [Medline: 26963569]

11. Hsieh C, Nelson DL, Smith DA, Peterson CQ. A comparison of performance in added-purpose occupations and rote exercise for dynamic standing balance in persons with hemiplegia. Am J Occup Ther 1996 Jan;50(1):10-16. [doi: 10.5014/ajot.50.1.10] [Medline: $\underline{8644831]}$

12. Wee JY, Bagg SD, Palepu A. The Berg balance scale as a predictor of length of stay and discharge destination in an acute stroke rehabilitation setting. Arch Phys Med Rehabil 1999 Apr;80(4):448-452. [doi: 10.1016/s0003-9993(99)90284-8] [Medline: 10206609$]$

13. de Niet M, Weerdesteyn V, de Bot ST, van de Warrenburg BP, Geurts AC. Does calf muscle spasticity contribute to postural imbalance? A study in persons with pure hereditary spastic paraparesis. Gait Posture 2013 Jun;38(2):304-309. [doi: 10.1016/j.gaitpost.2012.12.006] [Medline: 23433545]

14. Cakar E, Durmus O, Tekin L, Dincer U, Kiralp MZ. The ankle-foot orthosis improves balance and reduces fall risk of chronic spastic hemiparetic patients. Eur J Phys Rehabil Med 2010 Sep;46(3):363-368 [FREE Full text] [Medline: 20927002]

15. Wei T, Liu P, Chang L, Liu S. Gait asymmetry, ankle spasticity, and depression as independent predictors of falls in ambulatory stroke patients. PLoS One 2017;12(5):e0177136 [FREE Full text] [doi: 10.1371/journal.pone.0177136] [Medline: $\underline{28542281]}$

16. Rahimzadeh Khiabani R, Mochizuki G, Ismail F, Boulias C, Phadke CP, Gage WH. Impact of Spasticity on Balance Control during Quiet Standing in Persons after Stroke. Stroke Res Treat 2017;2017:6153714 [FREE Full text] [doi: 10.1155/2017/6153714] [Medline: 29098109]

17. Ansari NN, Naghdi S, Moammeri H, Jalaie S. Ashworth Scales are unreliable for the assessment of muscle spasticity. Physiother Theory Pract 2006 Jun;22(3):119-125. [doi: 10.1080/09593980600724188] [Medline: 16848350]

18. Fleuren J, Voerman GE, Erren-Wolters CV, Snoek GJ, Rietman JS, Hermens HJ, et al. Stop using the Ashworth Scale for the assessment of spasticity. J Neurol Neurosurg Psychiatry 2010 Jan;81(1):46-52. [doi: 10.1136/jnnp.2009.177071] [Medline: 19770162]

19. Abolhasani H, Ansari NN, Naghdi S, Mansouri K, Ghotbi N, Hasson S. Comparing the validity of the Modified Modified Ashworth Scale (MMAS) and the Modified Tardieu Scale (MTS) in the assessment of wrist flexor spasticity in patients with stroke: protocol for a neurophysiological study. BMJ Open 2012;2(6) [FREE Full text] [doi: 10.1136/bmjopen-2012-001394] [Medline: 23166123]

20. Salbach NM, Mayo NE, Hanley JA, Richards CL, Wood-Dauphinee S. Psychometric evaluation of the original and Canadian French version of the activities-specific balance confidence scale among people with stroke. Arch Phys Med Rehabil 2006 Dec;87(12):1597-1604. [doi: 10.1016/j.apmr.2006.08.336] [Medline: 17141639] 
21. Ghotbi N, Nakhostin Ansari N, Naghdi S, Hasson S. Measurement of lower-limb muscle spasticity: intrarater reliability of Modified Modified Ashworth Scale. J Rehabil Res Dev 2011;48(1):83-88 [FREE Full text] [doi: 10.1682/jrrd.2010.02.0020] [Medline: 21328165]

22. Nakhostin Ansari N, Naghdi S, Forogh B, Hasson S, Atashband M, Lashgari E. Development of the Persian version of the Modified Modified Ashworth Scale: translation, adaptation, and examination of interrater and intrarater reliability in patients with poststroke elbow flexor spasticity. Disabil Rehabil 2012;34(21):1843-1847. [doi: 10.3109/09638288.2012.665133] [Medline: 22432437]

23. Naghdi S, Ansari NN, Azarnia S, Kazemnejad A. Interrater reliability of the Modified Modified Ashworth Scale (MMAS) for patients with wrist flexor muscle spasticity. Physiother Theory Pract 2008;24(5):372-379. [doi: 10.1080/09593980802278959] [Medline: 18821443 ]

24. Powell LE, Myers AM. The Activities-specific Balance Confidence (ABC) Scale. J Gerontol A Biol Sci Med Sci 1995 Jan;50A(1):M28-M34. [doi: 10.1093/gerona/50a.1.m28] [Medline: 7814786]

25. Khalifeloo M, Naghdi S, Ansari NN, Akbari M, Jalaie S, Jannat D, et al. A study on the immediate effects of plantar vibration on balance dysfunction in patients with stroke. J Exerc Rehabil 2018 Apr;14(2):259-266 [FREE Full text] [doi: 10.12965/jer.1836044.022] [Medline: 29740561]

26. $\mathrm{Ng} \mathrm{SS}$, Hui-Chan CW. The timed up \& go test: its reliability and association with lower-limb impairments and locomotor capacities in people with chronic stroke. Arch Phys Med Rehabil 2005 Aug;86(8):1641-1647. [doi:

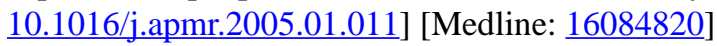

27. Nakhostin Ansari N, Naghdi S, Hasson S, Rastgoo M. Efficacy of therapeutic ultrasound and infrared in the management of muscle spasticity. Brain Inj 2009 Jul;23(7):632-638. [doi: 10.1080/02699050902973939] [Medline: 19557566]

28. Lin S, Hsu L, Wang H. Effects of ankle proprioceptive interference on locomotion after stroke. Arch Phys Med Rehabil 2012 Jun;93(6):1027-1033. [doi: 10.1016/j.apmr.2012.01.019] [Medline: 22503933]

29. Balasubramanian CK, Bowden MG, Neptune RR, Kautz SA. Relationship between step length asymmetry and walking performance in subjects with chronic hemiparesis. Arch Phys Med Rehabil 2007 Jan;88(1):43-49. [doi: 10.1016/j.apmr.2006.10.004] [Medline: 17207674]

30. Lin P, Yang Y, Cheng S, Wang R. The relation between ankle impairments and gait velocity and symmetry in people with stroke. Arch Phys Med Rehabil 2006 Apr;87(4):562-568. [doi: 10.1016/j.apmr.2005.12.042] [Medline: 16571398]

31. Kerrigan DC, Karvosky ME, Riley PO. Spastic paretic stiff-legged gait: joint kinetics. Am J Phys Med Rehabil 2001 Apr;80(4):244-249. [doi: 10.1097/00002060-200104000-00002] [Medline: 11277129]

32. Yang J, Kim S. Correlation of knee proprioception with muscle strength and spasticity in stroke patients. J Phys Ther Sci 2015 Sep;27(9):2705-2708 [FREE Full text] [doi: 10.1589/jpts.27.2705] [Medline: 26504273]

\section{Abbreviations \\ ABC: Activities-Specific Balance Confidence \\ ANOVA: analysis of variance \\ MAS: Modified Ashworth Scale \\ MMAS: Modified Modified Ashworth Scale \\ ROM: range of motion \\ TUG: Timed Up and Go}

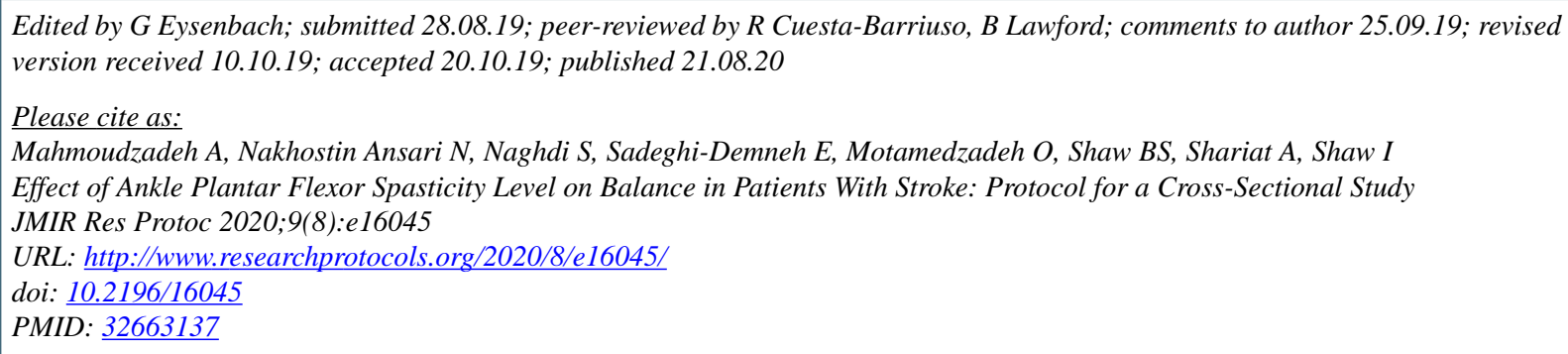

(C)Ashraf Mahmoudzadeh, Noureddin Nakhostin Ansari, Soofia Naghdi, Ebrahim Sadeghi-Demneh, Omid Motamedzadeh, Brandon S Shaw, Ardalan Shariat, Ina Shaw. Originally published in JMIR Research Protocols (http://www.researchprotocols.org), 21.08.2020. This is an open-access article distributed under the terms of the Creative Commons Attribution License (https://creativecommons.org/licenses/by/4.0/), which permits unrestricted use, distribution, and reproduction in any medium, provided the original work, first published in JMIR Research Protocols, is properly cited. The complete bibliographic information, 
a link to the original publication on http://www.researchprotocols.org, as well as this copyright and license information must be included. 